\title{
Validation of a liquid chromatography ultraviolet method for determination of herbicide diuron and its metabolites in soil samples
}

\author{
ANA LUCIA S.M. FELICIO, ALESSANDRA M. MONTEIRO, MARIANA B. ALMEIDA, \\ TIAGO B. MADEIRA, SUZANA L. NIXDORF and MARIA JOSEFA S. YABE
}

Universidade Estadual de Londrina, Departamento de Química, Rod. Celso Garcia Cid, Km 380, 86057-970 Londrina, PR, Brasil

Manuscript received on March 27, 2015; accepted for publication on March 18, 2016

\begin{abstract}
Diuron is one of the most widely herbicide used worldwide, which can undergo degradation producing three primary metabolites: 3,4-dichlorophenylurea, 3-(3,4-dichlorophenyl)-1-methylurea, and 3,4-dichloroaniline. Since the persistence of diuron and its by-products in ecosystems involves risk of toxicity to environment and human health, a reliable quantitative method for simultaneous monitoring of these compounds is required. Hence, a simple method without preconcentration step was validated for quantitation of diuron and its main metabolites by high performance liquid chromatography with ultraviolet detection. Separation was achieved in less than 11 minutes using a $\mathrm{C}_{18}$ column, mobile phase composed of acetonitrile and water $(45: 55 \mathrm{v} / \mathrm{v})$ at $0.86 \mathrm{~mL} \mathrm{~min}^{-1}$ and detection at $254 \mathrm{~nm}$. The validated method using solid-liquid extraction followed by an isocratic chromatographic elution proved to be specific, precise and linear $\left(\mathrm{R}^{2}>0.99\right)$, presenting more than $90 \%$ of recovery. The method was successfully applied to quantify diuron and their by-products in soil samples collected in a sugarcane cultivation area, focusing on the environmental control.
\end{abstract}

Key words: pesticides, degradation products, HPLC-UV, soil, environmental control.

\section{INTRODUCTION}

Demand for quality as many as quantity of food in general requires the use of chemicals for fighting invasive weeds and pests. However, there is a concern that these toxic pesticides once introduced into environment, affect ecosystem conservation, as well as human and animal health (Stasinakis et al. 2009).

Among different types of pesticides, diuron (3-(3,4-dichlorophenyl)-1,1-dimethylurea) is one

Correspondence to: Maria Josefa Santos Yabe

E-mail: mjyabe@uel.br of the most widely used herbicide in Brazil. It is extensively employed for pre- and post-emergent weed control in cotton, sugarcane, citrus and pineapple cultivation areas, also being applied in non-cultivation areas as roads and railways (Gondim-Tomaz et al. 2005, Giacomazzi and Cochet 2004). As a consequence, it can be found in groundwater, surface water and sediments, originating from soil leaching (Blanchoud et al. 2004). Due to its low water solubility (42 $\mathrm{mg} \mathrm{L}^{-1}$ at $25^{\circ} \mathrm{C}$ ) and high sorption capacity to organic matter, this herbicide is relatively persistent in soil with 
half-life of 1 month to 1 year (Giacomazzi and Cochet 2004, Field et al. 2003).

According to toxicity degree and environmental hazard, diuron is considered moderately toxic and dangerous to environment. U.S. Environmental Protection Agency (EPA) has classified this herbicide as a "known/likely" carcinogen since 1997. Furthermore, diuron may be a precursor of nitrosodimethylamine, a compound belonging to N-nitrosamine family with high carcinogenic potential (Chen and Young 2008, Di BernardoDantas et al. 2011). Although most of the toxicity studies focuses on herbicide, degradation products can represent an environmental risk. According to Tixier et al. (2001), diuron can undergo transformations forming by-products with even greater toxicity. Its degradation in environment mainly occurs through microorganism biological activity, producing three primary metabolites: 3,4-dichlorophenylurea (DCPU), 3-(3,4-dichlorophenyl)-1-methylurea (DCPMU), and 3,4-dichloroaniline (DCA) (Dalton et al. 1996, Cox et al. 2007). These by-products can persist longer in aquatic and terrestrial ecosystems due to its great stability (Tixier et al. 2000, Sorensen et al. 2003). Since main breakdown product (DCA) is considered more toxic and persistent in the environment than diuron itself (Giacomazzi and Cochet 2004), analytical methods able to detect diuron and its metabolites are extremely important.

High performance liquid chromatography (HPLC) has been widely used to analyze pesticides, including diuron determination in water, soil and sediment (Martinez and Barceló 2001, Lourencetti et al. 2008, Chaplain et al. 2001, Balakrishnan et al. 2012, Tworkoski et al. 2000). Due to analyte low concentration levels comprising interfering diversity, pesticides in water determined by HPLC usually requires the use of very sensitive detectors (such as mass spec's) and involves preconcentration steps which can take over half of the total analysis time (Stork et al. 2008, Brondi and
Lanças 2005, Azevedo et al. 2001, Gallitzendorfer et al. 2011). However, diuron and its by-products can be monitored in soil from cropping areas by using sensitivity and reasonable cost equipment as ultraviolet detectors (UV). The evaluation of these compounds under field conditions, such as farming areas, is useful to assist in studies of sorption, desorption, degradation and transport of this analytes in different types of soil. Thus, the aim of this study was to validate a simple and reliably HPLC-UV method using solid-liquid extraction followed by an isocratic chromatographic elution for direct simultaneous quantitation of diuron and its three main metabolites.

\section{EXPERIMENTAL}

\section{CHEMICALS AND REAGENTS}

DCPU, DCPMU, diuron and DCA analytical standards were purchased from Dr. EhrenstorferSchafers Laboratory (Augsburg, Germany) with purity around 99\%. Acetonitrile and methanol (HPLC grade) were obtained from J.T. Baker (Phillipsburg, NJ, USA). High purity water was obtained from a Millipore Milli $Q^{\circledR}$ purification system (Billerica, MA, USA).

\section{SAMPLING SITE AND SAMPLE PREPARATION}

Soil samples were collected in a sugarcane cropping area located in the countryside of Porecatu municipality, Paraná State, Southern Brazil. In addition, a soil sample from a nearby preserved forest was used as a blank sample.

Each soil sample was milled in porcelain mortar applying pestle and sieved through two mesh of $9(2.0 \mathrm{~mm})$ and $250(63 \mu \mathrm{m})$ (Bertel Ind. Metalúrgica, Caieiras, SP, Brazil). For extraction of diuron and its metabolites, $10 \mathrm{~mL}$ of methanol were added to $5.00 \mathrm{~g}$ of sample and kept overnight in an end-over-end shaker at $24^{\circ} \mathrm{C}$. The soil extracts were centrifuged at $1200 \mathrm{rpm}$ for $30 \mathrm{~min}$ and 5.0 
$\mathrm{mL}$ of each supernatant was filtered through a $0.22 \mu \mathrm{m}$ polytetrafluoroethylene (PTFE) membrane (Millipore Corporation, Cork, Ireland) directly into glass vials, and storage at $4^{\circ} \mathrm{C}$ until further use.

\section{INSTRUMENTATION}

Herbicide diuron and its metabolites were analyzed by HPLC using a Waters Alliance ${ }^{\circledR}$ e2695 Separations Module (Milford, MA, USA) equipped with degasser, quaternary solvent organizer pump, autosampler and a Waters 2998 photodiode array detector. Separations were performed using a XTerra $\mathrm{C}_{18}$ column $(4.6 \times 250 \mathrm{~mm}, 5 \mu \mathrm{m})$ from Waters Corporation. Data acquisition and treatment were performed using an Empower $2.0^{\circledR}$ software package.

VALIDATION AND QUANTITATION

The proposed HPLC-UV method was based on a procedure for determination of diuron and its metabolites in water (Field et al. 1997). In order to ensure reliable results, a method was validated in terms of specificity, selectivity, linearity, accuracy, repeatability, intermediate precision, limit of detection (LOD), and limit of quantitation (LOQ).

Diuron and its metabolites quantitation was performed by external standard method. Analytical curves were acquired by solutions standards injection prepared with methanol in concentration range from 0.05 to $35.1 \mathrm{mg} \mathrm{L}^{-1}$ (DCPU, DCPMU and diuron) and 1.60 to $35.1 \mathrm{mg} \mathrm{L}^{-1}$ (DCA). All determinations in soil samples were performed in triplicate.

\section{RESULTS AND DISCUSSION}

\section{METHOD VALIDATION}

For the proposed HPLC-UV method in isocratic elution mode each standard of interest (DCPU, DCPMU, diuron, and DCA) was injected observing suitable resolution, without soil matrix interference and co-elution in retention times. Characteristic spectra were checked for each compound. Ideal analytical conditions able to promote separation for four analyte of interest were obtained using a mobile phase composed by water and acetonitrile

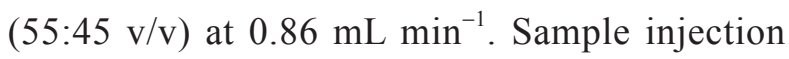
volume was $20 \mu \mathrm{L}$ with detection done at $254 \mathrm{~nm}$. Column and injector temperature were maintained at $30^{\circ} \mathrm{C}$ and $20^{\circ} \mathrm{C}$, respectively. In these conditions, analyte separations were archived in less than 11 $\min$.

Compared to the method developed by Field et al. (1997) it was not necessary to use gradient elution to separate compounds of interest and analysis time was reduced considerably. An isocratic HPLCUV method to analyze diuron and its metabolites in calcareous soil was presented by Gooddy et al. (2002). However, according to those authors, the sample preparation was more laborious, including two types of extractions, requiring even methanol evaporation and suspension with water; separation was performed in about 20 minutes. Moreover, post-run backflushing due to the amount of injected sample $(1 \mathrm{~mL})$ was demanded to prevent column carry-over.

Specificity and selectivity of the proposed method was investigated using soil sampled in preserved area (reference). Chromatograms obtained by injections of reference sample (Fig. 1a) and standard solution (Fig. 1b) showed absence of analytical response, regarding reagents or interfering species in retention time of the peaks of compounds of interest.

To assess the linearity, random injections of standard mixtures in triplicate were performed to allow analytical curves construction. Working range and information concerning to linear data regression analysis are presented in Table I. Coefficients of determination $\left(R^{2}\right)$ were higher than 0.99 , which indicate that regression line perfectly fits the experimental data, showing a linear response over concentration range tested. 

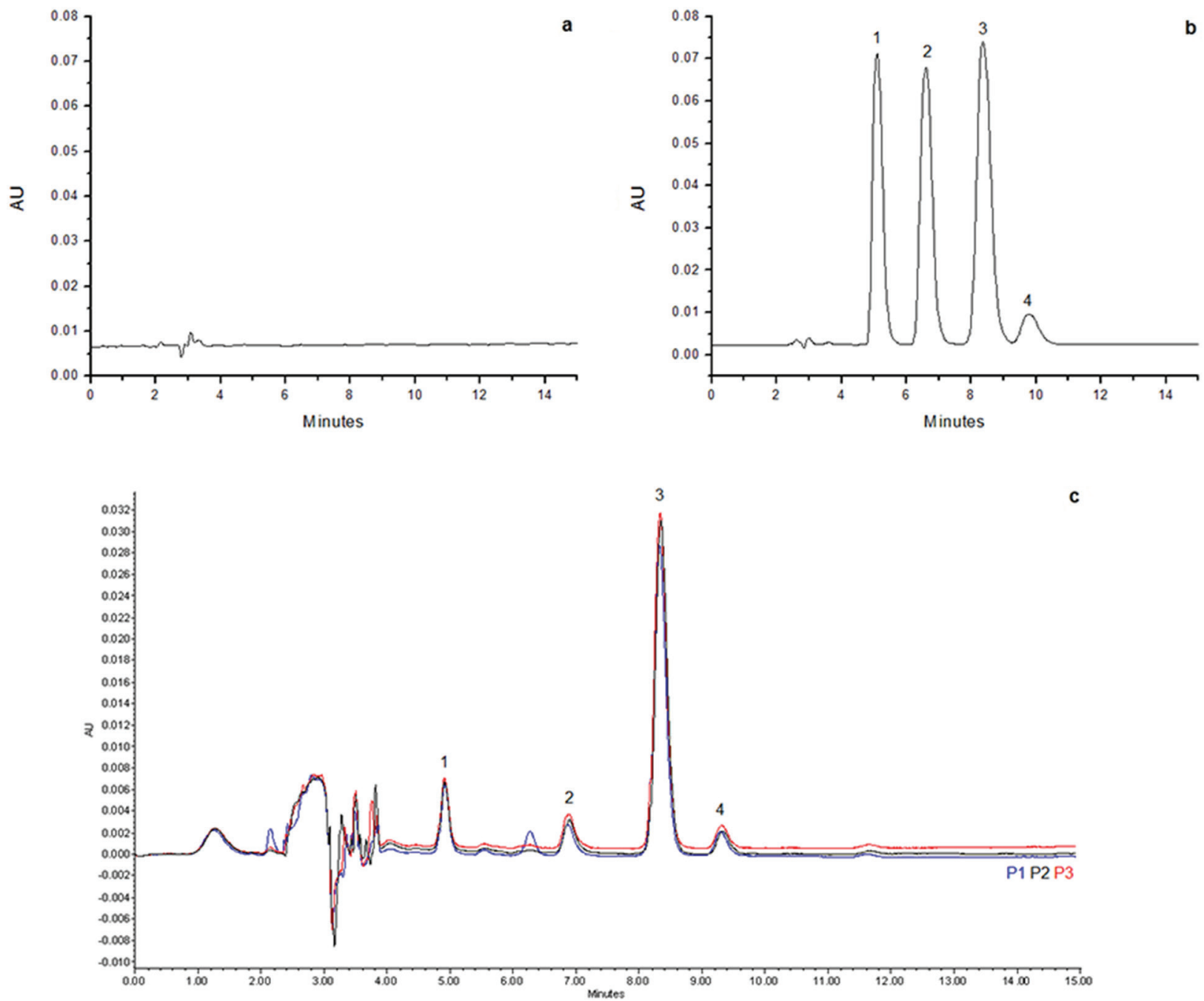

Figure 1 - (a) Chromatogram of preserved area soil sample used as a reference. (b) Chromatogram of analytical standards mixture at an individual concentration of $9.6 \mathrm{mg} \mathrm{L}^{-1}$. (c) Chromatograms of three soil samples collected in a sugarcane cultivation area. Analytes: DCPU (1), DCPMU (2); diuron (3), and DCA (4). Mobile phase: water:acetonitrile (55:45 v/v); flow rate: $0.86 \mathrm{~mL} \mathrm{~min}^{-1}$; injection volume: $20 \mu \mathrm{L}$; column: XTerra $\mathrm{C}_{18}(4.6 \times 250 \mathrm{~mm}, 5 \mu \mathrm{m}) ; \lambda: 254 \mathrm{~nm}$.

The limits of detection (LOD) and quantification (LOQ) of diuron and its metabolites were estimated considering a signal-to-noise $(\mathrm{S} / \mathrm{N})$ ratio of 3 and 10, respectively, according to the International Committee on Harmonization Q2(R1) for HPLC methods validation (ICH 2005). The values of LOD and LOQ obtained from dilutions of a standard mixture are shown in Table I. In addition, soil samples from a preserved area (blank) were spiked with known amounts of analytical standards and subjected to the solid-liquid extraction procedures. The extract was evaluated by HPLC-UV and successively diluted until the peaks of the compounds were barely observed in the chromatogram. In this condition, the lowest detectable and quantifiable concentrations for the analytes in the soil were $0.02,0.01,0.04$ and $0.05 \mathrm{mg} \mathrm{kg}^{-1}$ and $0.07,0.04$, 0.13 and $0.13 \mathrm{mg} \mathrm{kg}^{-1}$ for DCPU, DCPMU, diuron, and DCA, respectively. 
TABLE I

Parameters of linear regression, limits of detection (LOD) and quantitation (LOQ) for diuron and the metabolites (n=3).

\begin{tabular}{|c|c|c|c|c|c|}
\hline Analyte & $\begin{array}{c}\text { Working } \\
\text { Range }\left(\mathrm{mg} \mathrm{L}^{-1}\right)\end{array}$ & $\begin{array}{c}\text { Linear Regression } \\
\text { Equation }\end{array}$ & $\begin{array}{c}\text { Coefficient of } \\
\text { Determination }\left(R^{2}\right)\end{array}$ & $\begin{array}{c}\text { LOD } \\
\left(\mathrm{mg} \mathrm{L}^{-1}\right)\end{array}$ & $\begin{array}{c}\text { LOQ } \\
\left(\mathrm{mg} \mathrm{L}^{-1}\right)\end{array}$ \\
\hline DCPU & $0.05-35.1$ & $150992 x+20592$ & 0.99993 & 0.01 & 0.03 \\
\hline DCPMU & $0.05-35.1$ & $129016 x-509$ & 0.99996 & 0.01 & 0.02 \\
\hline Diuron & $0.05-35.1$ & $196603 x+12985$ & 0.99993 & 0.02 & 0.05 \\
\hline DCA & $1.60-35.1$ & $35848 x-50263$ & 0.99020 & 0.02 & 0.07 \\
\hline
\end{tabular}

DCPU: 3,4-dichlorophenylurea; DCPMU: 3-(3,4-dichlorophenyl)-1-methylurea; DCA: 3,4-dichloroaniline.

Analytical method accuracy, indicating nearness between expected value and experimental value found, was assessed using blank soil samples spiked with standard solutions at low, medium and high concentration levels (Table II). The fortified samples were subjected to the solid-liquid extraction procedures. After extraction, aliquots were analyzed and the experimental data were statistically evaluated by analyte recovery rates. Average percentages of recovery performed in triplicate were 91.9, 92.1, 94.4 and 90.1\% for DCPU, DCPMU, diuron, and DCA, respectively.

TABLE II

Accuracy given by recovery of the proposed method for different levels of analyte concentration.

\begin{tabular}{ccc}
\hline Compound & $\begin{array}{c}\text { Concentration } \\
\left(\mathbf{m g ~ L}^{-1}\right)\end{array}$ & Mean $\pm \mathbf{S D}, \mathbf{n}=\mathbf{3}$ \\
\hline \multirow{3}{*}{ DCPU } & 0.4 & $84.2 \pm 2.8$ \\
\cline { 2 - 3 } & 9.6 & $91.0 \pm 6.6$ \\
\hline \multirow{3}{*}{ DCPMU } & 20.0 & $100.5 \pm 4.4$ \\
\cline { 2 - 3 } & 0.4 & $82.8 \pm 4.3$ \\
\hline \multirow{3}{*}{ Diuron } & 9.6 & $92.8 \pm 1.5$ \\
\cline { 2 - 3 } & 20.0 & $100.6 \pm 2.9$ \\
\cline { 2 - 3 } & 0.4 & $86.6 \pm 2.1$ \\
\hline \multirow{3}{*}{ DCA } & 9.6 & $91.4 \pm 1.7$ \\
\cline { 2 - 3 } & 20.0 & $105.3 \pm 3.6$ \\
\cline { 2 - 3 } & 1.6 & $98.1 \pm 7.3$ \\
\hline & 9.6 & $94.6 \pm 6.1$ \\
\hline
\end{tabular}

DCPU: 3,4-dichlorophenylurea; DCPMU: 3-(3,4-dichlorophenyl)-1-methylurea; DCA: 3,4-dichloroaniline.
Precision of the developed method was assessed with respect to repeatability (intraday precision) and intermediate precision (interday precision) by standard solutions replicate injections $(n=6)$. Coefficients of variation (CV) were determinate through data statistical treatment. In both precision tests, CV was greater for low concentration solutions. The $\mathrm{CV}$ values obtained for repeatability test were $1.89,1.15$ and $1.85 \%$, respectively, for DCPU, DCPMU and diuron at $0.4 \mathrm{mg} \mathrm{L}^{-1}$ and $1.43 \%$ for DCA at $1.6 \mathrm{mg} \mathrm{L}^{-1}$. The intermediate precision assay showed $\mathrm{CV}$ values of $3.51,3.34$ and $3.76 \%$, respectively, for DCPU, DCPMU and diuron at $0.4 \mathrm{mg} \mathrm{L}^{-1}$ and $4.29 \%$ for DCA at $1.6 \mathrm{mg}$ $\mathrm{L}^{-1}$. Thus, the method can be considered precise, since CV for all measures were below 5\%.

\section{QUANTITATIVE ANALYSIS IN SOIL SAMPLES}

The validated method was applied to real soil samples from sugarcane cropping area. Figure 1c shows chromatograms corresponding to the samples collected in three different points around 20 meters far from each other, without the addition of analytical standards. The identification of diuron and its metabolites was based on the retention times (Fig. 1b) in addition to the comparison of its UVVIS spectrum profiles in the same chromatographic conditions.

Quantitative analyses were performed using external standard method, by comparing peak areas of samples with standard solutions. Concentration 
of each compound of interest in the sample is shown in Table III.

Analyzed compounds presented low variation regarding to concentration in the soil samples (Table III). It is worth to emphasize that sample preparation was conducted without any pre- concentration or dilution step, since the studied analytes were within validated working range. Moreover, interfering compounds were not observed in the sample matrix, which ensures the applicability of the proposed method in real soil samples.

TABLE III

Concentration of diuron and its metabolites in sugarcane soil samples.

\begin{tabular}{ccccc}
\hline \multirow{2}{*}{ Sample } & \multicolumn{4}{c}{ Concentration $\left(\mathbf{m g ~ k g}^{-1}\right)(\mathbf{M e a n} \pm \mathbf{S D}, \mathbf{n}=\mathbf{3})$} \\
\cline { 2 - 5 } & DCPU & DCPMU & Diuron & DCA \\
\cline { 2 - 4 } P1 & $0.88 \pm 0.04$ & $0.20 \pm 0.02$ & $3.91 \pm 0.19$ & $3.98 \pm 0.02$ \\
P2 & $0.86 \pm 0.02$ & $0.23 \pm 0.03$ & $4.16 \pm 0.16$ & $4.12 \pm 0.61$ \\
P3 & $0.82 \pm 0.01$ & $0.22 \pm 0.01$ & $3.89 \pm 0.09$ & $4.15 \pm 0.14$ \\
\hline
\end{tabular}

DCPU: 3,4-dichlorophenylurea; DCPMU: 3-(3,4-dichlorophenyl)-1-methylurea; DCA: 3,4-dichloroaniline. SD: standard deviation; P: sampling point.

\section{CONCLUSIONS}

This paper reports a validated simple HPLC-UV method for simultaneous determination of herbicide diuron and its metabolites (DCPU, DCPMU, DCA) in soil. Chromatographic separation was performed in less than 11 minutes using isocratic mode after an extraction that does not require pre-concentration steps. Validated parameters as specificity, selectivity, linearity, sensitivity, accuracy and precision, proved that this method can be useful for diuron and its main by-products quantitation being applicable to soil samples in field condition. Therefore, the proposed method represents a reliable and feasible potential tool to monitoring, in an easy way, the persistence of diuron and its metabolites in environment.

\section{ACKNOWLEDGMENTS}

The authors would like to thank the Conselho Nacional de Desenvolvimento Cientifico e Tecnológico (CNPq, Brasília, Brazil) and Coordenação de Aperfeiçoamento de Pessoal de Nível Superior (CAPES, Brasília, Brazil) for their financial support and fellowships.

\section{REFERENCES}

AZEVEDO DA, LACORTE S, VIANA P AND BARCELÓ D. 2001. Analysis of priority pesticides and phenols in Portuguese river water by liquid chromatography-mass spectrometry. Chromatographia 53:113-118.

BALAKRISHNAN S, TAKEDA K AND SAKUGAWA H. 2012. Occurrence of Diuron and Irgarol in seawater, sediments and planktons of Seto Inland Sea, Japan. Geochem J 46: 169-177.

BLANCHOUD H, FARRUGIA F AND MOUCHEL JM. 2004. Pesticide uses and transfers in urbanized catchments. Chemosphere 55: 905-913.

BRONDI SHG AND LANÇAS FM. 2005. Development and validation of a multi-residue analytical methodology to determine the presence of selected pesticides in water through liquid chromatography. J Braz Chem Soc 16: 650653.

CHAPLAIN V, BARRIUSO E, DUR JC AND VERGNET C. 2001. Influence of the formulation on the sorption and the mobility of diuron in soil. Environ Contam Tox 66: 664-670.

CHEN W AND YOUNG TM. 2008. NDMA formation during chlorination and chloramination of aqueous diuron solutions. Environ Sci Technol 42: 1072-1077.

COX L, VELARDE P, CABRERA A, HERMOSÍN MC AND CORNEJO J. 2007. Dissolved organic carbon interactions with sorption and leaching of diuron in organic-amended soils. Eur J Soil Sci 58: 714-721.

DALTON RL, EVANS AW AND RHODES RC. 1996. Disappearance of diuron from cotton fields soils. Weeds 14 31-33. 
DI BERNARDO-DANTAS A, PASCHOALATO CFR, MARTINEZ MS, BALLEJO RR AND DI BERNARDO L. 2011. Removal of diuron and hexazinone from Guarany Aquifer groundwater. Braz J Chem Eng 28: 415-424.

FIELD JA, REED RL, SAWYER TE, GRIFFITH SM AND WIGINGTON PJ. 2003. Diuron occurrence and distribution in soil and surface and ground water associated with grass seed production. J Environ Qual 32: 171-179.

FIELD JA, REED RL, SAWYER TE AND MARTINEZ M. 1997. Diuron and its metabolites in surface water and ground water by solid phase extraction and in-vial elution. J Agr Food Chem 45: 3897-3902.

GALLITZENDORFER R, TIMM T, KOCH D, KUSTERS M AND GERHARTZ M. 2011. Simultaneous determination of 12 sulfonylurea herbicides in drinking water after SPE by LC-DAD. Chromatographia 73: 813-816.

GIACOMAZZI S AND COCHET N. 2004. Environmental impact of diuron transformation: a review. Chemosphere 56: 1021-1032.

GONDIM-TOMAZ R, DURRANT L AND FRANCO T. 2005. Biodegradation of Diuron and Pyruthiobac-Sodium by White-Rot and Soil fungi. In: Calabrese EJ, Kostecki PT and Dragun J (Eds), Contaminated Soil, Sediments and Water: Science in the Real World, Springer, Berlin, Germany, p. 21-32.

GOODDY DC, CHILTON PJ AND HARRISON I. 2002. A field study to assess the degradation and transport of diuron and its metabolites in a calcareous soil. Sci Total Environ 297: 67-83.

ICH. 2005. International Conference on Harmonization of Technical Requirements for Registration of Pharmaceuticals for Human Use, Q2(R1): Validation of Analytical Procedures: Text and Methodology.
LOURENCETTI C, MARCHI MRR AND RIBEIRO ML. 2008. Determination of sugar cane herbicides in soil and soil treated with sugar cane vinasse by solid-phase extraction and HPLC-UV. Talanta 77: 701-709.

MARTINEZ K AND BARCELÓ D. 2001. Determination of antifouling pesticides and their degradation products in marine sediments by means of ultrasonic extraction and HPLC-APCI-MS. Fresenius J Anal Chem 370: 940-945.

SORENSEN SR, BENDING GD, JACOBSEN CS, WALKER A AND AAMAND J. 2003. Microbial degradation of isoproturon and related phenylurea herbicides in and below agricultural fields. FEMS Microbiol Ecol 45: 1-11.

STASINAKIS AS, KOTSIFA S, GATIDOU G AND MAMAIS D. 2009. Diuron biodegradation in activated sludge batch reactors under aerobic and anoxic conditions. Water Res 43: 1471-1479.

STORK PR, BENNETT FR AND BELL M. 2008. The environmental fate of diuron under a conventional production regime in a sugarcane farm during the plant cane phase. Pest Manag Sci 64: 954-963.

TIXIER C, BOGAERTS P, SANCELME M, BONNEMOY F, TWAGILIMANA L, CUER A, BOHATIER J AND VASCHAMBRE H. 2000. Fungal biodegradation of a phenylurea herbicide, diuron: Structure and toxicity of metabolites. Pest Manag Sci 56: 455-462.

TIXIER C, SANCELME M, BONNMOY F, CUER A AND VESCHAMBRE H. 2001. Degradation products of a phenylurea herbicide, diuron: Synthesis, ecotoxicity, and biotransformation. Environ Toxicol Chem 20: 1381-1389.

TWORKOSKI TJ, WELKER WV AND VASS GD. 2000. Soil residues following repeat applications of diuron, simazine, and terbacil. Weed Technol 14: 191-196. 